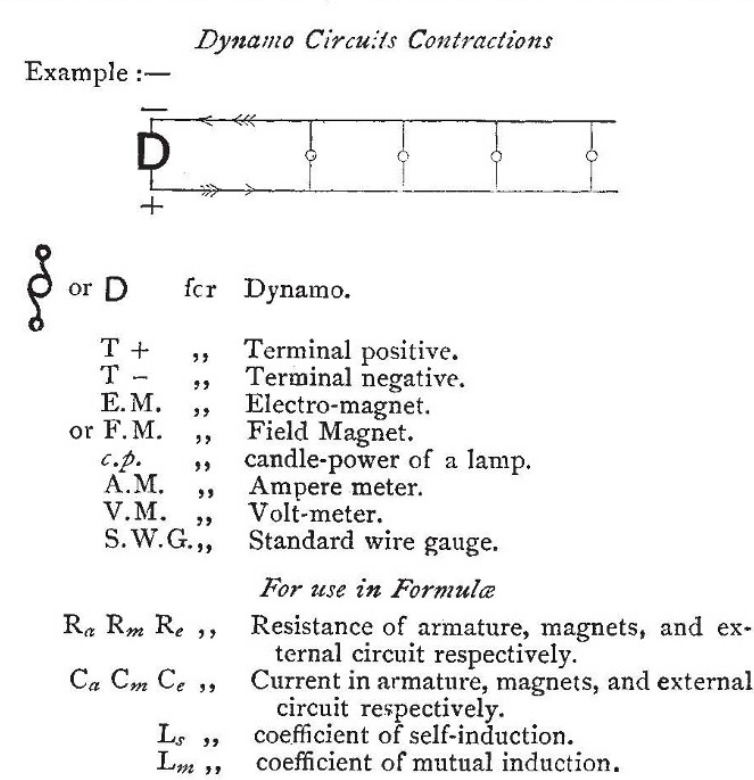

In the above notation the first letter of the most important words has been used wherever it was found practicable to do so, and the recurrence of the same letter under similar circumstances avoided as much as possible. In cases where no ambiguity can occur, such as $\mathrm{H}$ for the heat in Joules, and $\mathrm{H}$ for the horizontal intensity of the terrestrial magnetism; $m$ for metre, and $m$ for magnetic strength of pole; $\mathrm{V}$ for velocity, and $\mathrm{V}$ for volts, it will be observed that the same letters appear in each case.

M. Hospitalier, the Secretary for the French Committee on this subject, came over from Paris specially to take part in the discussion, and related what had already been done by him in Paris.

Prof. Forbes, Mr. John Munro, Prof. Ayrton, Dr. Fleming, Prof. Hughes, Prof. Silvanus Thompson, and others took part in the discussion, and generally agreed that a uniform system was much required. The paper, they said, had given a very fair start to this being accomplished.

The author replied that he was glad the Society had agreed so readily to form a thoroughly representative committee, and hoped that their work would be not only speedily accomplished but satisfactory to all concerned.

\section{THE JUBILEE OF THE STATISTICAL SOCIETY}

THE Statistical Society has been holding a series of meetings during the present week in celebration of the jubilee of its foundation. The meeting is really an International Congress of Statistics, some of the most eminent foreign statisticians being present as the guests of the Society ; among others Sig. Bodio, of Rome; MM. Keleti, Körösi, and Prof. Neumann-Spollart, of Buda-Pesth ; Prof. Levasseur and M. de Foville, of Paris Gen. F. A. Walker, of the United States, Gen. Liagre, and others. The meetings have been held in the theatre of London University, and several subjects of much statistical importance have been introduced for discussion. One of them was the claim of statistics to be considered as a science, discussed at some length in the address of the President, Sir Rawson W. Rawson. Statistics, as usually treated in this country, little more than the mere calculating of numbers, is a mere mechanical operation; but which, treated as some of the most eminent statists have treated it, as dealing with the structure of human society, then it certainly becomes amenable to scientific methods. Sir Rawson Rawson referred further to the want of organisation in the collection and publication of official statistics in this country, and rightly advocated reform in this respect. Among the other papers read on Monday were-a sketch of the history of the Society, by Dr. F. J. Mouat; "Statistical Developments, with special reference to Statistics as a Science," by Dr. W. A. Guy, F.R.S. ; and on "Statistics and their Enemies," by M. de Foville. One of the principal papers on Tuesday was by Mr. R. Giffen, on "Some General Uses of Statistical Knowledge," in which, among other things, he referred to the rapid increase of the population of Europe during the last century as compared with the increase in China and other Asiatic countries (except India) and in Africa. Should the present rate of European increase continue, the population of our continent in another century will be 1000 millions, whilst that of the United States would be 800 millions. Mr. Giffen maintained that the increase in Europe had been accompanied by a corresponding increase in the means of subsistence and improvement in the position of all classes.

Mr. J. S. Jeans read a paper "On Uniformity of Statistics." $\mathrm{He}$ held the chief desiderata required with a view to the improvement and co-ordination of the statistical work undertaken by different Government bureaux were: (I) an agreement as to the major facts necessary to be collected for each special department of statistics ; (2) uniformity in the processes by which these facts were got together; (3) co-ordination of the methods whereby the materials thus collected were systematised and made use of ; (4) the adoption, as far as possible, of the calendar year as the universal statistical period, so that when comparisons were made they should alway relate to the same dates ; $(5)$ the general adoption of the metrical system of weights, measures, and currency.

Herr Körösi spoke "On the Unıfication of Census Record Tables." The voluminous and polyglot census results of the world were, he found, practically non-comparable, and he proceeded to sketch a uniform scheme of record tables by which we should arrive at one bound at the highest aim of statistics-the possession of a uniform description of the different nations and of all mankind as regarded sex, age, civil state, illiteracy, occupations, \&c.

Mr. F. Y. Edgeworth, in a paper entitled "The Methods of Statistics," confined himself to the treatment of numerical means. He showed that if we take several means of phenomena belonging to one and the same class (e.g. statures of men), each mean derived from numerous observations, the set of values thus presented would in general /fulfil a certain simple mathematical law. The general formula involved a constant or coefficient peculiar to each class of phenomena, which must be discovered by experience. When this operation had been performed we had an apparatus for testing whether any given mean was or was not exceptional, indicative that the set of things of which the datum was the mean might ( (as compared with other phenomena of the same general class) be regarded as belonging to a distinct species. A pretty illustration of important principles was afforded by the statistics of a wasp's nest, "the image of trade which wasps entering and issuing from their nest present." It appeared that the exports and imports of this miniature commerce fluctuated with mathematical regularity. As further illustrations of the variety of interests amenable to the general law, he adducer the attendance of the members of a club at a talle d'hote, and the frequency of dactyls in the Latin hexameter. The conditions postulated by the Calculus of Probabilities were particularly well exemplified by the fluctuations of the Virgilian rhythm. In conclusion, he alluded to the simpler methods of statistics, and maintained that the mathematical, as compared with the more elementary, organon could produce the same effect with less trouble, or, with the same trouble, greater effect.

M. Emile Levasseur, Member of the Institute and Professor at the College of France, initiated a discussion on the graphic method applied to statistics, exhibiting diagrams and cartograms or statistical maps illustrating his views. Prof. Marshall, of Cambridge, who followed, advocated the use of a standard gauge for historical curves in order to simplify references to the graphic method of statistics, and pointed out dangers in the employment of curves arising from their deceptive appearance to the untrained eye. He suggested a ready means of testing the values of curves under comparison.

Yesterday was entirely occupied by a conference and discussion on the subject of an International Statistical Institute, the establishment of which was virtually agreed to.

\section{UNIVERSITY AND EDUCATIONAL INTELLIGENCE}

CAmbridge. - At the annual election at St. John's College on June 22, the following awards were made to students of Mathematics, Natural Science, and Medicine :-

Foundation Scholarships.-Mathematics: Love, Fletcher 
(each raised to rool.), Bushe-Fox, Kirby, Mossop, Foster Hill. Natural Science and Medicine: Shore, Rolleston, Seward.

Exhibitions.-Mathematics : Holnes, Middlemast, Pressland, Roseveare, Bushe-Fox, Foster, Flux. Natural Science and Medicine: Rolleston, Olive, Jones. Natural Science: Evans, Rendle, Lake.

Proper Sizarships.-Mathematics : Norris, Varley.

Hughes Prizes.-Mathematics: Love. Natural Science: Shore.

Wright Prizes,-Mathematics: Fletcher, Bakre, and Flux (equal).

Herschel Prize (for Astronomy).-Bushe-Fox.

Hockin Prize (for Electricity). - Not awarded.

The Hutchinson Studentship (NATURe, May 28, p. 90) was awarded to Ds. Rapson (First Class, Classical Tripos I883-85, and Indian Languages Tripos I885) to assist him in the prosecution of his studies in Sanskrit literature.

The next Adams Prize will be adjudged in 1887. The subject is Ellipsoidal and Spheroidal Harmonic Analysis, attention being particularly drawn to the reduction of the formulæ in this calculus to practical forms adapted to numerical calculation. Since, with the exception of spherical harmonics, this method has remained almost barren in physical investigations, actual illustrations of its utility are invited. The essays must be sent in by December 16, I886, and any Cambridge graduate may compete. The successful candidate will receive $\mathrm{r}$ 70l.; he must print the essay at his own expense.

The Mathematical Board recommend that four separate examiners be appointed for the final portion of the Mathematical Tripos, in the hope of inducing more specially qualified professors and specialists to undertake this advanced work.

The Annual Report of the Observatory gives a very satisfactory record of progress. Among the 3253 observations with the transit circle were 2442 of zone stars on roo nights, the greater number at five or seven wires, and all read off with four microscopes. The reductions of observations are in a forward state.

At the Botanical Gardens during the past year the collection of insectivorous plants has been greatly improved. A number of new or rare species have flowered-some for the first time in this country. A speciality has been made of Salvia, and four species from this garden have been figured in the Botanical Magazine.

A grant not exceeding Iool. is to be made to C. S. Sherrington, M.B., of Gonville and Caius College, from the Wort Travelling Scholars Fund, to enable him to proceed to Valentia to investigate the experiments now being made by Dr. Ferrand on inoculation as a preventive against cholera.

\section{SCIENTIFIC SERIALS}

IN the Fournal of Botany for May and June Mr. W. B Grove continues his paper on " new or noteworthy fungi," which is well illustrated. Several new species are described, and one new genus, Diplococcium, near to Cladotrichum.-Mr. S. Le M. Moore identifies Bacterium fortidum, Thin, found in association with profuse sweating of the soles of the feet, with the ordinary micrococcus of surface soil.-Mr. H. N. Dixon adds a new species to the British moss flora, Catharinea dixoni, from Northampton.-Mr. R. D. Fitzgerald and Mr. H. N. Ridley describe new Orchids; and Rev. B. Scortechini a new genus of Myrtaceæ, Pseudoerigenia, from the Malay Peninsula.-Dr. H. Trimen sends some notes on the flora of Ceylon, and Rev. W. H. Purchas contributes notes on Dovedale plants.

Rivista Screntifico Industriale, May 15.-A new explanation of the red after-glows (continued), by Prof. Cario Marangoni. On the diathermicity of fluids, by A. Volta. - Some electric phenomena associated with rarefied gases, by Emilio Piazzoli. Variations in the electric resistance of solid and pure metal wires according to the temperature (concluded), by Prof. Angelo Emo.

Bulletin de l'Académie Royale de Belgique, April 4.-Crystallographic note on some specimens of calcite from the Carboniferous limestone of Blaton. - Note on the recent appearance of a school of whales (Balana biscayensis) on the east coast of the United States, by M. P. J. Van Beneden.-Account of the discovery of a gigantic Mosasaurian (Hainosaurus) in the chalk formation of Mesvin-Ciply near Mons, Belgium, by M. E Dupont.-On Riccati's equation and its double generalisation, by M. J. de Tilly. - State of the vegetation during the month of
Marçh at Liége and Longchamps-sur-Geer, Belgium, by Baron de Selys Longchamps.-On the presence of Condroz graywacke in the neighbourhood of Beaumont, Entre-Sambre-et-Meuse, by M. Michel Mourlon.-On the porphyries of Bierghes, by M. A. Renard.-On the tension of saturated vapours : a modification of the atomic law of Dalton, by M. P. de Heen.-The Roumanians in the Middle Ages: a historical puzzle, by M. A. D. Xenophol.

\section{SOCIETIES AND ACADEMIES LONDON}

Royal Society, June 18.- "The Action of Tidal Streams on Metals during Diffusion of Salt and Fresh Water. Experimental Research, Part II. (Gravimetric)." By Thomas Andrews, F.R.S.E. Communicated by Prof. G. G. Stokes, Sec.R.S.

In a paper last session on " The Electromotive Force during Diffusion in Tidal Streams" (see Proc. Roy. Soc., No. 232), the author recorded the electrical part of this investigation. The present communication contains the concluding gravimetric experiments of the research. The effects attending the diffusion of the salt and fresh water in tidal estuaries, on parts of the same metal, of known composition and general properties, were estimated in each case for a period of one year, during which bright plates of the following metals-viz., wrought iron (combined carbon, none), " soft" Bessemer steel (c.c. 0.15), "soft" Siemens-Martin steel (c.c. $0^{\circ} 17$ ), "soft" cast steel (c.c. 0.46 ), "hard" Bessemer steel (c.c. 0'5I), best cast metal, "No. I" (c.c. 0*39), common cast metal, “No. 2 " (c.c. 0.67 ), were constantly exposed to conditions of galvanic action similar to those obtaining in some tidal streams. The results demonstrate that electric disintegration of the nature alluded to in this and the former paper (viz., the galvanic destructive action on parts of even the same metal, arising from difference of electrical potential during diffusion between the surface and lower waters in a tidal stream) is, on comparison with other investigations by the author, apparently of much greater extent than the loss either from simple corrosion in sea water alone, or than that which ensues from the action on each other of dissimilar metals of this group (such as wrought irons, cast metals, and steels) in galvanic connection in sea water. Compared with simple corrosion in sea water only, the increase in loss varied from about 15 up to 50 per cent., according to the nature of the metals. The results of the experiments in this and the former paper indicate, therefore, that the tidal action on any vessel or metallic structure, of sea and fresh water whilst diffusing is (in the case even of the same metal thus exposed to the simultaneous action of top and bottom waters) considerably more destructive in its nature and character than the action of sea water alone. Moreover, the author has found it (in other experiments) extending over long periods to considerably exceed (in some instances varying from about 55 to I20 per cent.) the loss caused by galvanic action between dissimilar metals of the iron and steel group in circuit in sea water.

Geological Society, May 27.-Prof. T. G. Bonney, F.R.S., President, in the chair--George Ormond Kekewich was elected a Fellow of the Society. - The following communications were read:-On the so-called diorite of Little Knott (Cumberland), with further remarks on the occurrence of Picrites in Wales, by Prof. T. G. Bonney, F.R.S., Pres.G.S. The Little Knott rock and its microscopic structure were briefly described by the late Mr. Clifton Ward, who named it a diorite, but called attention to its abnormal character. The author gave some additional particulars, and showed that, although the rock varies in different parts of the same outcrop, and is not one of the most typical representatives of the picrite group, its relations on the whole are with this rather than with the true diorites. He also called attention to the extraordinary number of boulders which have been furnished by this comparatively small outcrop, and discussed the relation of their distribution to the former extension and effects of ice in the Lake District. He briefly noticed the occurrence of additional boulders of picrite in Anglesey, and described specimens from two localities (Caemawr and Pengorphwysfa) where a similar rock has been discovered in situ by Prof. Hughes. Hence it is probable that the Anglesey boulders are derived from localities in that island, and not from Cumberland. From a re-examination of specimens collected by the late Prof. Sedgwick and Mr. Tawney, preserved in the Woodwardian Museum at Cambridge, the author showed that the rock must occur in situ in two localities in the Lleyn 